Article

\title{
Correlation of Knowledge as a Basic Element for Generating Tourism Sustainable Projects in Rural Communities
}

\author{
Gomez Monica ${ }^{1}$, Palmas Daniela ${ }^{2 *}$ Jimenez- Ruiz Andrea ${ }^{3}$, Serrano- Barquin Rocío ${ }^{4}$ and Osorio \\ Rebeca ${ }^{5}$, \\ 1 Faculty of Tourism and Gastronomy, Universidad Autonoma del Estado de México; \\ moniss060495@gmail.com \\ 2 Faculty of Tourism and Gastronomy, Universidad Autonoma del Estado de México \\ 3 Faculty of Tourism and Gastronomy, Universidad Autonoma del Estado de México; \\ andreaedurnejr@gmail.com \\ 4 Faculty of Tourism and Gastronomy, Universidad Autonoma del Estado de México; \\ rocioserba@yahoo.com.mx \\ 5 Faculty of Tourism and Gastronomy, Universidad Autonoma del Estado de México; \\ velabequi@hotmail.com \\ Correspondence: hashir04@hotmail.com; Tel.: +52 1 7225504834(JRA, S-BR)
}

\begin{abstract}
According to the growing concern of various focus groups, in regard to the mitigation of the negative impacts generated because of the tourism, has born the interest of proposing sustainable tourism projects derivatives of the feeling within the communities (1) Background: the aim is to propose a differentiated diagnosis of the Subsystems (biophysical and anthropic) and their relationship with traditional-rational knowledge; (2) Methods: from the Theory of Complex Systems was propose the Harmonic Tourism Methodology, that try to correlation the subsystem and knowledge in the community of San Juan Tlahuica Atzingo, State of Mexico (4) Conclusions: Among the most outstanding results that are on the one hand, we must work through tourism projects to the rescue and preservation of natural and cultural resources, reassessing them through the strengthening of social cohesion. On the other hand, the application of this case allowed us to visualize that it is necessary to consolidate the elements and steps of the methodology in order to apply it to different communities that are beginning their journey in the field of the tourism and that can improve and potentiate their resources, seeking harmony between them.
\end{abstract}

Keywords: harmonic methodology tourism; sustainability attributes; rural tourism; knowledge; complex systems

\section{Introduction}

Tourism is a complex phenomenon that is constantly seeking for the enjoyment and knowledge of the culture as well the appreciation of the beauty of the landscapes, beaches, jungles, rivers, among other natural resources through increased contact with host communities and nature. The activity generates positive impacts such as foreign exchange contribution, employment generation, contribution to regional development, revitalization of the cities that have lost their origins and identity, among others (CNET, 2016); however, it also contributes to generate negative impacts on the environment (Jimenez, 1982; Acerenza, 2006) and communities.

Given the concern of some research groups, NGOs, governments and communities in general, to reduce the negative impacts, with the proposal consolidates sustainability, suggesting changes in behavior and values of tourists, as well in the whole population, emerging new forms of tourism that are opposed to mass tourism, generating sun and beach destinations that are focused in the rescue 
and preservation of natural and cultural resources. Facing this situation, the need arises to think of another way of doing tourism, study and above all to plan better (Palmas, et al, 2017).

For a new way of tourism, come up new methodologies that are helping to the incoming tourism projects, such as the case of the Harmonic Tourism Methodology (HTM) proposed by Palmas (2017), which is integrated in the Theory of Complex Systems of Rolando Garcia (2006). The main goal in the first period, allowed to have a diagnosis based on the interrelationship of knowledge of scientific communities as well as rural and suburban communities in San Pedro de Quiroga Tultepec, State of Mexico.

Starting from the experience, it was developed the harmonic tourism project, it was proposed a methodology to get the appreciation of natural and cultural resources in the State of Mexico, registered in the Ministry of Public Education of Mexico, which derives in the present manuscript, which has strengthened the main goal looking to improve the quality of life of the community through the tourism as a complementary activity. The first part of the manuscript begins with the conceptualization of tourism and the role of rural tourism as a strategy for local development, then it returns to the harmonic tourism and its linkage with complex systems and knowledge as an important element. Then the territorial space analysis as a complex system (CS) continuing with the methodological section and finishing with the final results of the research.

\subsection{Tourism, different conceptualizations in the research for harmony.}

Alternative tourism is one of the role models that aims to combat social inequality as well as the local and foreign influences that are involved within the communities (Gascon, 2012). Ibañez and Ivanova (2012) presuppose that the organizers are aware of the natural, social and community values, and tourists want to interact with the local population (p. 22). Also, making experiences where the tourist is able to be part of recreational activities in direct contact with the nature and the cultural expressions of rural, indigenous and urban communities, respecting the resources (SECTUR, 2004).

Particularly rural tourism, emerged in Europe in the fifties, as an alternative activity to recover the natural areas affected by the World War II. The main representative's countries were Germany, France, Spain and England. In the late eighties, from the impulse to the Common Agricultural Policy (CAP) of the European Union, rural tourism becomes relevant as an extra source of income and property taxes activity (Olivera et al; 2009).

In Latin America, the lack of rural development, poverty and exclusion led to reconsider whether the road was right. Since the 2000 year, governments adjusted their policies integrating strategies for rural development based on a territorial approach, promoting the development and diversification of secondary activities in the agricultural sector. Therefore, the increase of rural tourism is given by two factors: the sectoral crisis that encourages farmers to seek for other alternatives, and displaying an increasing demand of tourism as a dynamic sector (Roman and Ciccolella, 2009).

In Mexico specifically, the National Support Fund for Social Enterprises (NSFSE) was the pioneer of rural tourism and during the nineties, supported directly eleven states of the country, most of them with high rates of indigenous and rural poverty. In addition to NSFSE, other institutions and programs such as the National Institute of Indigenous Towns (NIIN), which has also supported the promotion of rural tourism through the program of alternative tourism in indigenous areas (Garduño, Guzman and Villareal, 2009; CDI, 2011).

Rural tourism also was inserted into the political area, is presented as an ally to the ideals of sustainable development. Among the elements that stand out in this type of tourism know-how is something remarkable, ruling as a guiding principle of sustainability of resources and the weighting of local knowledge, authenticity and territorial identity (Thomé- Ortíz, 2007; Nogar and Capristo , 2010; Pérez and Zizumbo, 2014 and Osorio et al, 2015)..

Specialists as Blanco and Hernando (2003), Barrera (2006), Requier (2006), Bullón and Bullón (2008) and Roman and Ciccolena (2009), agree that rural tourism should include enjoyment of the natural environment, coexistence with the host community and the dynamic practice of typical activities in rural areas. Taking into consideration the knowledge from communities and know-how, 
which provides a duality with the territory, so that knowledge is practical and is not intended to seek for explanations (Agüero, Urtubey and Vera, 2008; Velarde, 2014). In this duality, should be integrated the "being", as being-know-do, explicit knowledge ranging from generation to generation, who have internalized, creating an identity forged in the roots of the community.

The being-know-do, the harmonic tourism presents itself as a global and inclusive element, which calls for the development processes into the touristical destinations, resulting in the generation of social and economic benefits for the host communities. It involves the assessment of the ethical principles arising in a model of development based on the respect for environment and society (Serrano- Barquin et al, 2010: 973).

Serrano-Barquin, has worked since 2006 in this conceptualization because this axis considers the economic, social, cultural and natural dimensions. For the social perspective, it is necessary to strengthen the elements of the local production system, and the people involved in participating directly in the provision of services. For the social dimension to be considered as welfare, organization and participation of social partners needs to reach a balanced development. The cultural dimension considers: feeding habits, clothing and social relationships (Costa Drinking, de Araujo and Menasche, 2018), as main elements that are necessary to study, in order that society suits their nature. Therefore the natural dimension, is considered as the basis of life, and without tourism, would be no sense of existence and potential (Serrano-Barquin, 2006).

Bringing the concept of harmonic tourism as an ideology (or methodology), there is an interrelation between the principles of sustainability, and environmentally intuitive-rational use, the principle of complementarity and complex systems, which can promote development of local communities, education interrelate, culture, economic organization and urban development among others, with an interactive planning participant. In this context, the harmonic tourism can contribute as a complementary activity in rural areas, it can help to diversify and generate products and services derived from the linking traditional-rational knowledge from different spatial and temporal scales, integrating biophysical and anthropic subsystems to rescue in harmony the already mentioned subsystems (Palmas, et al.2018).

\subsection{The integration of knowledge for the harmonious tourism.}

The integration of knowledge leads to work under the premise of harmony between them and that proposals containing identity and concord, which is not an easy path to follow. The dialogue of knowledge makes necessary to dissolve the dichotomy between modern and traditional, giving rights to the traditional practices (Leff, 2002), placing nature as the basis of dialogue, permeating in the recursion of rational and traditional knowledge.

In order to achieve a dialogue of knowledge, two types of knowledge are framed: rational knowledge, which involve a whole historical process and travels through time looking for improvement, always willing to find reasonable explanations to events, emerging from the communities of scientists and researchers; and traditional knowledge, which also has a historical process; however, it travels in the timeline learning to respect knowledge and identities, and is not looking for rational explanations and emerges from popular knowledge (Leff, 2006).

Traditional knowledge, have a connotation that epistemologically interweaves holistically with the cultural identity of communities and indigenous peoples is a learned knowledge and apprehended, acquired from nature, natural medicine, culture and folklore (WIPO, 2002; 2018); and traditional knowledge is knowledge and socially appropriate technologies which have generally solved problems in health, work, food, etc." (Semanate and León, 2012: 262). These knowledge there are two types, traditional and vernacular, the difference can emerge from the root of the word vernacular, which it comes from the Latin vernaculus, it means "born in the house of one" and tradition comes from traditio, which it means that is transmitted through the generations (Royal Spanish Academy, 2016). What is significant is to recognize that the knowledge emanating from the communities is a knowledge that must come to dialogue with rational knowledge.

Then, in the dialogic sense based on the complex association of knowledge (Morin, 2005), the traditional can remain as a complementary concept, recursive knowledge of communities, but which 
in turn includes the vernaculars of these skills. In the complexity, tradition is hologrammatic, can be immersed in everything, for systemic study in the Harmonic tourism, sub-elements contain essentially, the whole to correlate the biophysical and anthropic subsystems (Palmas et al., 2014). Which means, that tradition is the whole, it is in its parts and those parts are those that comprise (hologramatic principle) and give essence and continuity through paradigms and subjects.

\subsection{Complex systems and tourism.}

Harmonic tourism, must be considered in all the spheres that integrate the CS that is being studied, for this to happen the community must be considered as a CS, dynamic and non-linear, in which the parts must be analyzed individually, without losing sight of its hologramatic parts and have everything to be separated into sub-elements to study, its essence is immersed.

Nonlinearity, allows an interrelation and analysis of all the systemic elements that are comprised. A CS in words of Garcia(2006) is a cut of reality, considered as a whole, so because of that it has an order and organization level, and can be composed of $n$ number of elements. For Grimm and Calabrese (2011), the properties that comprise the CS, emerge over time and to identify systems and their behaviors. So, a community, its characteristics and elements can be studied from this vision.

For the integration of a CS should be consider the observables, which are the data emanating from the experience; events, which are the observable facts, interdefinibility and interdependence, which are related to a mutual dependence of the functions performed by these elements within the total system (Garcia, 2006). It has three components: boundaries, elements and flows. The limits are placed delimiting the study of the system; however, pose no barriers, there remains an interaction with what is inside. The elements are interdefinable and serve to study the organization of the system. And finally the flows, which allow the interaction of the elements, regardless of whether they were inside or outside of the limits (ibdem).

Between the structural properties of the CS, they are exists adaptation, vulnerability and resilience. Adaptation is the process of decision and action to maintain the capacity to cope with current and future opportunities. Vulnerability is the susceptibility of the system to certain disturbances and the ability to adapt to such disturbances (Nelson et al., 2007, in Hall, Prayag and Amore, 2017). Resilience is the ability that it has whether the natural such as the cultural subsystem, to respond quickly to changes in a crisis or natural disaster (Hall, Prayag and Amore, 2017). Palmas et al. $(2014,2017)$ mention that the CS is a part of all to study, and to obtain a strengthened study should integrate the biophysical subsystems (Natural resources, the basis of life on this planet) and anthropic (created by human hands) to promote local development, as long as traditional and rational knowledge interweave and substantiate the sustainability of both subsystems.

The basic task to work, is to integrate sustainability into all aspects of daily life, but also in activities that have a strong impact as the tourism, so the interrelationships to substantiate a diagnosis to route this type of activities in communities, must be marked by the attributes of sustainability, among which are:

- Resilience: applied today from the natural and social environments, this attribute allows to recover the balance in different situations outside (Hall, Prayag and Amore, 2017; Guitérrez et al, 2014. Cuevas, 2010; Sancho and Guitiérrez, 2010; Twining Farrell-Ward, 2005)

- Adaptability: ability of a system to recover a stable state after a disturbance or affectation, the innovation facilitates this process (Martinez Piles, 2018; Herrera and Rodriguez, 2017, 2016; Sabatino, 2016)

- Equity: allows to distribute the social and economic benefits of tourism, improving the quality of life of the members (Ibanez and Los Angeles, 2012; Macário et al, 2013.;Sancho Garcia and Rozo, 2007; Vera Rebollo, 2001)

- Self-management: ability to distribute work, activities and tourism among all its members (Masera et al, 1999; Contreras, 2018; Gascon, 2016; Maldonado and Hernandez, 2011) 
- Productivity: ability to produce more material goods and wealth in certain time and in an area from inputs (Gutiérrez, 2013)

- Self-organization: mechanism through the one the system attempts to balance and distribute the activities and work, because of the social cohesion that sometimes allow resistance to disturbance agents, such as migration. (Herrera and Rodriguez, 2017; Argueta and Varela, 2014; Varisco, 2013, Somoza, 2011)

- Cost effectiveness: is the ability to generate earnings and profits (wealth) from certain costs through tourism projects in communities (Palmas, Serrano- Barquin and Gutierrez, 2014, Gutiérrez, 2013)

- Adoptability: is the system's ability to adopt technologies that do not harm the beliefs and customs, rather than allow their subsistence (Palmas, Serrano- Barquin and Gutiérrez, 2014, Salinas et al, 2013; Gutiérrez, 2013) and

- Institutional feasibility: ability to count on (government, educational and social) institutions that make viable, endorse and support projects (Palmas, Serrano- Barquin and Gutiérrez, 2014; Gutiérrez, 2013).

\section{Territory and Methodology}

In the municipality of Ocuilan different cultural expressions are developed from different ethnolinguistic groups, making complex to the communities that are located over there, just by the mere fact of being differentiated by the language that they speak and their ethnic identity. In the municipal and communities in the Southwest, inhabited ethnic groups of Nahuatl; however, the language disappeared in the early twentieth century, dissolving in speaking mestizo populations. That is, for years the community has faced a process of vulnerability, which begins with immersion and teaching of Spanish language and that, despite the time elapsed, in the northern part even an indigenous group called Tlahuica is preserved, it derived from a otomiana language (CDI, 2010).

This community is known as San Juan Atzingo, is located in the village of the same name, ranking, northeast of the county seat of Ocuilan de Arteaga, in the State of Mexico (Picture No. 1), to 2597 meters. It is nestled in mountains that surround and divide the basin of Mexico and Toluca Valley (Alvarez, 2006). From geographic information, it could be said, without making assertions that the resilience of this community due to the type of territory in which it is located and which has persisted over time with the characteristics that define it for its strong cultural rootedness.

It is settled around gaps Zempoala, the prevailing climate is temperate sub-humid with an average temperature of $15.5^{\circ} \mathrm{C}$. The monthly average rainfall is $83.8 \mathrm{~mm}$ in the period between June and September. Remarkably, July is the wettest of the year, when precipitation is reached to 258.2 $\mathrm{mm}$ (PMDU, 2004), which permits the existence of certain features in the type of soil, flora and fauna that predominates, and it has made the community to adapt and learn to subsist through the biophysical attributes subsystem offers.

It has two types of vegetation: Abies (fir) in the lagoons of Zempoala and mixed forest (pine and oak) in the hills that surround (CDI, 2010); however, for its great variety of species and richness of wood, currently the biotic element is vulnerable to systemic problems immoderate and illegal logging. However, there are records of 61 species of mammals, 231 of birds, reptiles 34,8 amphibians, fish 7, 1349 arthropod, highlighting some endemic species such as the mexcalpique and axolotl (PDM, 2014- 2018). 
Image 1. Location of San Juan Atzingo.

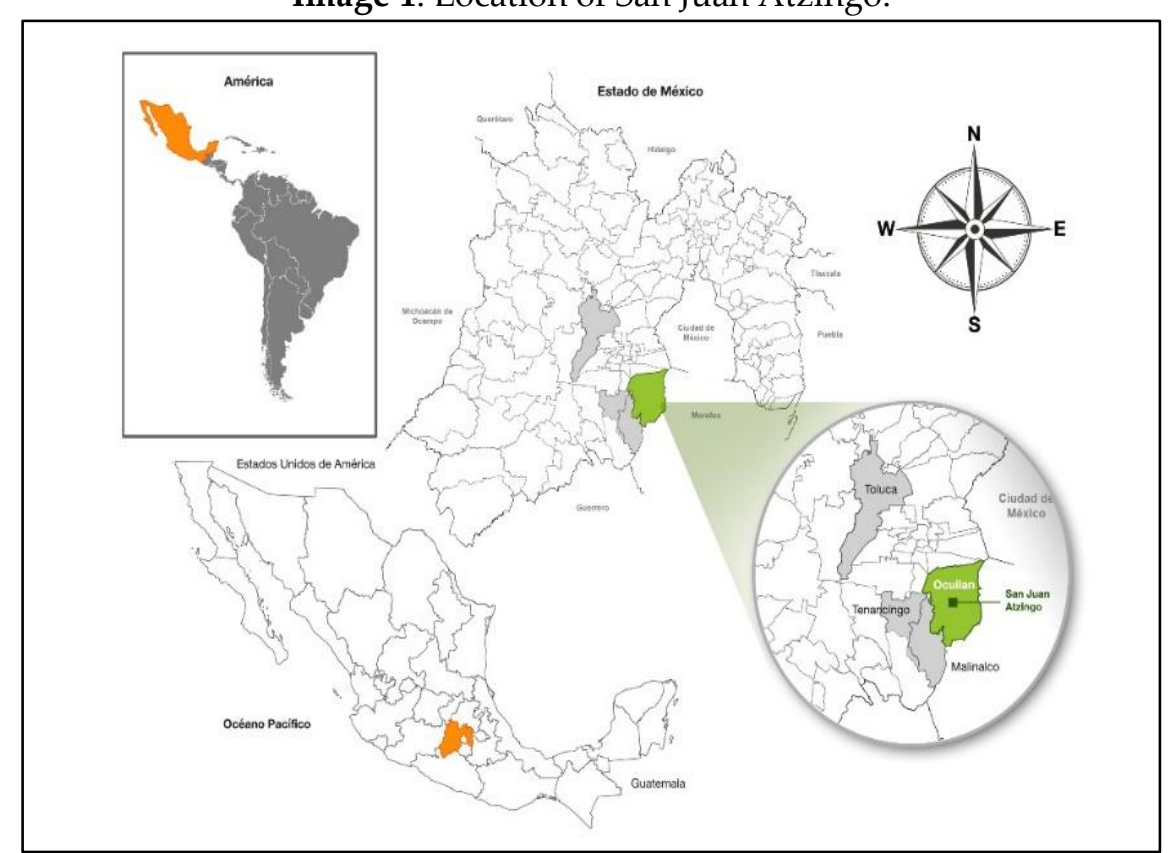

Prepared by: L. in Dis. José Alfredo Rosas Heredia.

Regarding population there are 436 men and 513 women. Around a $28.35 \%$ of the population is indigenous, and $10.54 \%$ of the population speaks an indigenous language (INEGI, 2010), which shows that even though a quarter of the population is indigenous, just a few are interested in learning to speak tlahuica. So it is necessary to work in linguistics, since it is a feature that has survived from generation to generation.

The community is governed by commons, which makes resources belong to the community, but on several occasions they have faced both external agents who put their safety, such as natural resources at risk. The assembly is commissioned to process financial resources from various agencies, it is composed of the president, secretary and treasurer of the Real de San Juan Atzingo, who are responsible for making representations to the environmental agencies. The assembly also is mainly used to address legal issues of territory, for the proper management of forests, care of illegal logging and generate self-employment within that territory.

Customs and traditions that have prevailed among different generations are what distinguishes the community from the rest of the populations and their cultural values that have emanated a distinct identity in the course of history; but they have faced hard challenges, groups have been formed for the preservation and rescue of two subsystems (biophysical and anthropic), which has not been easy because in Mexico, as in other Latin American countries, there is still a lack of development in rural areas and public policies that allow visualizing new alternatives for communities to prevail in time and space and could be known by future generations.

The HTM is based on the interrelationships between biophysical subsystem and the anthropic, the first includes everything that emanates from the nature and the second is constituted by society and its evolution over time and space. It is studied at three levels (micro, meso and macro), without neglecting the knowledge provided by the villagers, traditional knowledge and rational knowledge. The end of the interrelationship of knowledge with subsystems, systemic elements and attributes of sustainability is to generate concrete actions based on the feeling of the community and to promote local development.

The methodology arises from the methodological theoretical model proposed by Palmas et al. (2014) and Serrano-Barquin (2008), which are considered the categories of harmonic analysis tourism, local development, sustainability, biophysical and anthropic subsystems and traditional and rational knowledge. The phases of this methodology are five. In the first, the complex system to study defined, 
was delimited both spatially, and temporally, bearing in mind that the limits are not strict, for all correlates and interacts with other systems (Figure No. 1).

Figure 1. Integration and analysis of complex system

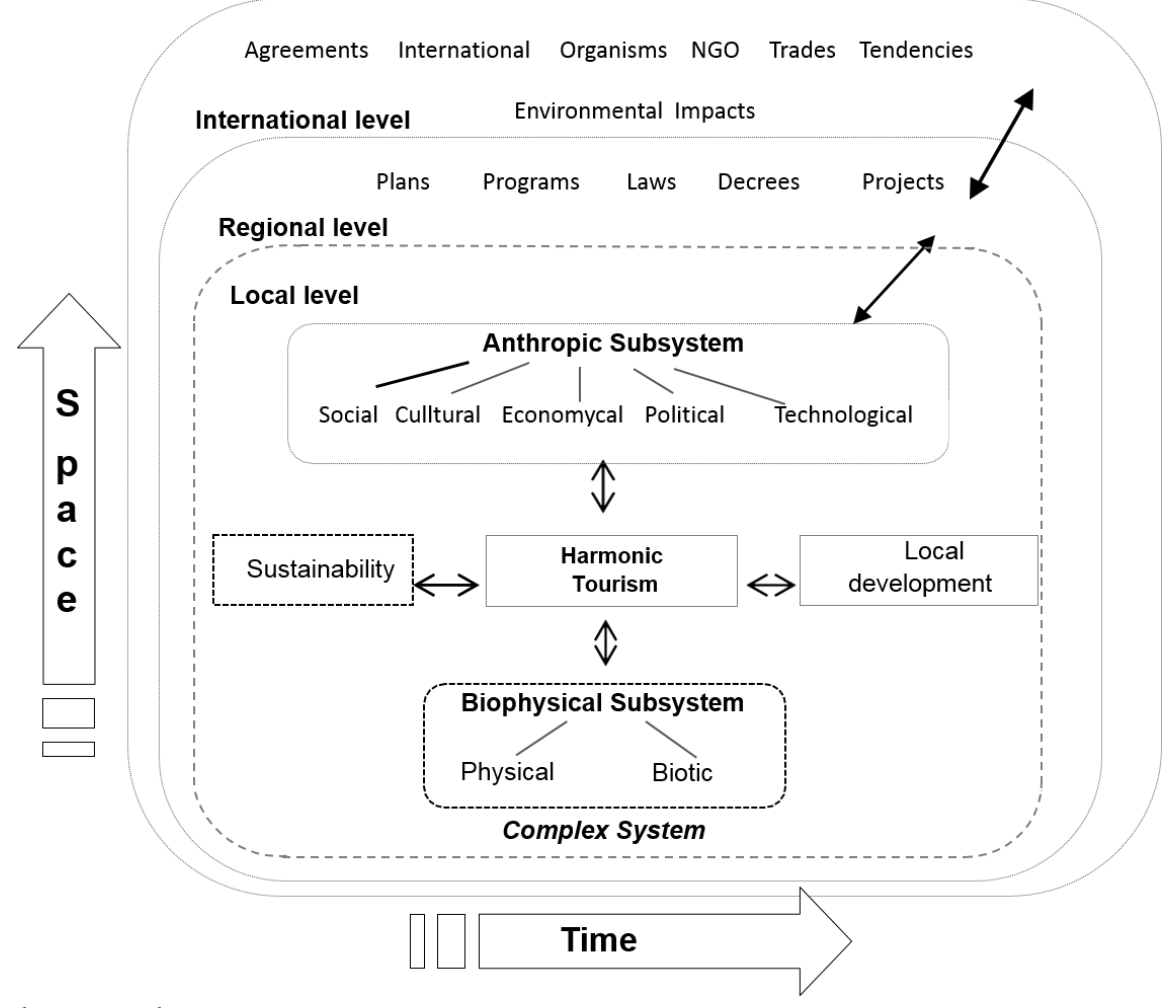

Source: Palmas et al., 2017.

In the second phase, the biophysical and anthropic subsystems information was collected, from the interrelationship between the rational and traditional knowledge. For rational, were analyzed scientific journal articles, development plans, books generated by the community, Regarding traditional knowledge nine semi-structured interviews were applied to key players whose characteristics were belong to the community and have extensive knowledge of the elements of each subsystem; direct observation was also made from several visits. In this phase Table No. 1 Diagnostics complex system is used.

Table 1. Diagnosis System Complex.

\begin{tabular}{|c|c|c|c|c|c|c|}
\hline $\begin{array}{c}\text { Subsys } \\
\text { tem }\end{array}$ & $\begin{array}{l}\text { systemic } \\
\text { elements }\end{array}$ & $\begin{array}{c}\text { systemic } \\
\text { subelement }\end{array}$ & $\begin{array}{c}\text { Sustainability } \\
\text { attribute }\end{array}$ & Rational evidence & $\begin{array}{l}\text { Traditional } \\
\text { evidence }\end{array}$ & Interpretation \\
\hline & \multirow{5}{*}{ Physical } & $\begin{array}{l}\text { geological } \\
\text { substrata }\end{array}$ & \multirow{7}{*}{ resiliency } & \multirow{8}{*}{$\begin{array}{l}\text { Literature review } \\
\text { of specialized } \\
\text { sources, books, } \\
\text { refereed journals, }\end{array}$} & & \\
\hline B & & $\begin{array}{l}\text { Relief } \\
\text { (geoformas) }\end{array}$ & & & & \\
\hline $\mathbf{i}$ & & Weather & & & & \\
\hline or & & Hydrology & & & & \\
\hline $\mathbf{F}$ & & Ground & & & & \\
\hline í & \multirow[b]{3}{*}{ biotic } & Wildlife & & & & \\
\hline s & & Flora & & & & \\
\hline $\begin{array}{l}\mathrm{i} \\
\mathrm{c}\end{array}$ & & & Adaptability & & $\begin{array}{l}\text { daily field } \\
\text { observation, }\end{array}$ & \\
\hline
\end{tabular}


8 of 16

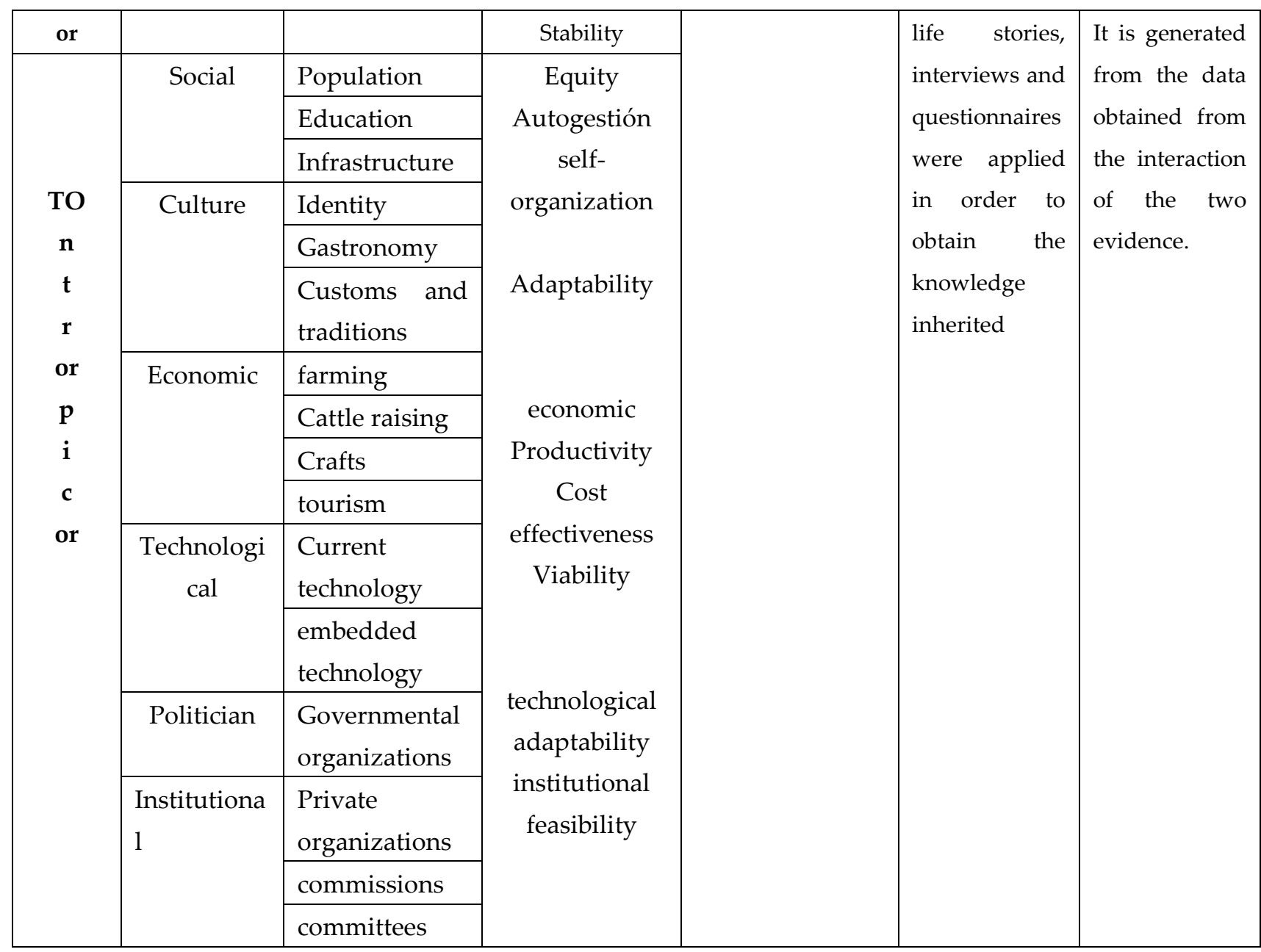

Source: Palmas et al, 2017.

In the third phase, the emerging problems from the community are analyzed and it interrelation of knowledge. To continue the fourth phase diagram of interrelationships, which are considered the different problems arising from this assessment, are organized from highest to lowest importance to display the focus. At last as fifth phase, possible alternatives to solve problems with concrete actions looking forward with the harmony between the two subsystems that are presented.

\section{Results}

Once done the research within the field, analyzed the scientific information and emptying the respective table's sources, the following interrelationships of biophysical and anthropic elements were identified.

\subsection{Interrelatedness of social-biotic-physical elements}

Although, soil properties with which the municipality has are rich in nutrients, allowing the harvest of different nourishment, to interrelate the sub-element population with the biophysical subsystem impacts of erosion occur by the excessive logging, which primarily affects the flora and wildlife of the wooded area in the Lagunas de Zempoala. Gaps, even though they are outside the system boundary, are correlated with the community; comprising more than three thousand hectares and is one of the main resources that provides water to the region.

In this sense there is a direct impact of excessive logging with the reproduction of species of biotic element, such as the case of wild edible mushrooms (WEM), among which are the saprobes, a species that is generated close to the trees. As mentioned Cristina 
when I was little, Lagunas had a lot of quantity and clean water, I think this was because the forest was more abundant, but with the problems of logging in addition to the neglect of people, gaps are not the same without forest because there are areas where no longer grow some resources, for example, some edible mushrooms, if there is no moisture do not grow (Cristina Carbajal, 2017).

The depth interviews, allows to visualize that not only in a scientifically way we can see that excessive logging is a negative natural resources, affecting water, flora and fauna impact. A favorable point is that, to come to realization, the community is looking to strengthen the collective consciousness to safeguard its resources through various cultural activities.

\subsection{Interrelation of physical elements biotics- cultural- polite elements}

Among the cultural systemic elements in the community, are still being used natural fertilizers such as animal manure, either cow or sheep, thereby finding a minimal impact on toxicity. These collective practices of fertilizer, have allowed WEM continue playing in the wild form, where no other activity is performed. The main problem in this respect, lies in the power executed by the political sphere, on social and biotic because of areas of use in agrochemicals for certain plantations were authorized, including agrochemicals sulfate or triple 16 is, which according rational knowledge point is very sensitive to high humidity (Fertinova, 2018), resulting to have a strong ability to take soil moisture into a powder.

Among inherited knowledge on natural resources, it finds the temporary planting of corn, green beans, bean, pea, carrot and serene. While the community practice this type of primary activity, collection of WEM, also characterizes to the community. There is a group of women who formed an association called Nebejolchjo Pjiekakjoo hongueras (Tlahuica Language), in english it means what I am. Acquired knowledge about WEMs has been passed from generation to generation, it use by selfconsumption and recently, with activities such as mycotourism (activity involves the identification and collection of various species of WEM, as well as recognition of their uses and main features according Jiménez-Ruiz et al; 2016; 2017).

As for the phenology (knowledge about dates of appearance of the WEM) have also been transmitted generationally and "is from late May to late August, or mid-September", the time when most abundant

,$"$ as the fungi depend on certain environmental conditions to fruition as humidity and temperature "(Eliseete Ramirez, 2018).

Within this season each species has its onset approximate dates, which are linked to the physical characteristics of the places where they are located, so the community is interested in the rescue and preservation of both as well as the language such as the fungi.

\subsection{Interrelation of physico-biotic- institutional-cultural elements}

As can be seen from the characterization of the territory, the resource that the community is starting to take, is related to the biophysical subsystem. In Mexico, have documented a total of 350 to 450 species of WEM (Sanchez and Mata, 2012), San Juan Atzingo has identified approximately 160 species, positioning it as one of the indigenous communities with an edible mycological resources of the country (Ramirez, 2017).

On the other hand, the cultural element that goes from generation to generation, has allowed to have knowledge of recollection, preparation method, and medicinal uses, related to the Tlahuica language, which is used to know the name of the fungus in both languages (Tlahuica and english) and allows to preserve the indigenous language.

San Juan Atzingo, has interrelation with the institutional element because it has support from agencies like the Protection of State Forests of Mexico (PROBOSQUE, by its initials in Spanish) and the Secretariat of Environment and Natural Resources (SERMARNAT, by its initials in Spanish), who have been supporting through the forest program persistent authorized a minimum of 10 years the benefit of the community as well for the surrounding communities. Other government institutions 
also work under different programs in the community are mainly the National Institute for Indigenous Peoples (INPI, by its initials in Spanish), Ministry of Social Development (SEDESOL, by its initials in Spanish), Secretariat of Agriculture, Livestock, Rural Development, Fisheries and Food (SAGARPA, by its initials in Spanish), the Commission Nacional Forestal (CONAFOR, by its initials in Spanish) and the national Commission of Natural Protected Areas (CONANP, by its initials in Spanish) from the latest, the community has received financial support to get materials, to develop tourism activities. It is noteworthy that the government has provided services to help the community, but the real advances have been generated by the local habitants and mushroom societies that were created.

And although they have government support for forest protection, problems of illegal logging:

in rare seasons it is difficult to make the mycotouristic tours, sometimes have been canceled because of the local mafia, led by X people who do not allow to us that we are the owners, get close to defend our resources for fear of reprisals occur. As it happened with a young man who was killed, four years ago, protecting our lands, being against excessive logging, even though the authorities which issued several demands supporters "(Anonymous, 62, 2017).

In regard, although there is not an actual record of all existing programs and beneficiaries for project generation, it is significant to notice, that any decision involving changes or improvement of any space within the community it is considered by the local population through an assembly.

Speaking about the element of institution and culture, there is a strong tradition that is still preserved in the community, which are the sacred poles and teponaztle with a head of a feline (it is a musical instrument like a drum, inherited from Mesoamerican cultures) both crafts are used in special events such as religious festivals and designation of authorities. The original teponaztle is stored in a box made of glass, because according to the mith:

"Teponaztle" tried to flee with her nanny, she lives in the Tepozteco, across the river, but the community caught it. Therefore is better to show to people who wants to see it, the exact same replica that it was made, and the original is guarded by the butler in charge "(Anonymous, 62, 2017).

\subsection{Interrelation of physical elements biotic- technological-Cultural}

Concerning the technological sub-element, the community has adapted to new technological tools for agriculture; however, still some established technologies like yoke, hoe, rake, shovel and peak still being used. Another element, where this link exists sub-element with the culture is in gastronomy, because there is no evidence of using the grinding stone, pestle, clay griddle, stove, pots and pans clay to prepare various dishes.

Systemic sub-element culture, is a differentiator sub-element, worthy of being studied as a whole system, since the Tlahuica language, also known as Atzinca or Ocuilteco, is spoken by 515 people in Mexico, of which over 10\% are located in San Juan Atzingo. Currently Tlahuica workshops where the language is taught in order to preserve it. "We feel very proud of our roots and traditions, when we do the tours gathering mushrooms with tourists, we try to dress them with the traditional clothes, plus always welcome them with phrases in the native anguage Tlahuica, for example kukendotsely means welcome" (Sergio Ramire, 2017).

This sub-element, is related with clothing, a few people of the community still using it and producing, for man it consists in wearing trousers and cotton shirt, huaraches and sash at the waist tangled, and they can be a different color. Woman costume is an embroidered white blouse with flowers and a chincuete of Cambay held with a multicolored sash. Also another cultural aspects that it has, is a variety of tangible and intangible as the Chinelos dance, the dance of the Horsemen and the Dance of the concheros attractions. Legends like deer and dead feast day. In addition, the expo fungus, is one of the events that are taking importance in the community. It takes place during august, and also it helps to spread the big variety of WEM as well as the traditional knowledge about them is disseminated.

Technological-cultural elements interrelatedness of economic 
Within the institutional element, it has a Municipal Development Plan (2014-2018), in which certain programs and projects for the recovery and preservation of culture are stipulated; one of the most important jobs that support information in the territory, is the thesis of WEM developed by Elissete Ramirez (2017), which is the preservation of culture collection, the Tlahuica language and gastronomy.

The cuisine of this community presents a dispute; since the results of rational research is documented, throw some dishes that currently do not exist or have ever done on this site, which was checked by the interviewees. Among the traditional dishes that are still preserved "is the Tsindatse, made of capulin, bone breaks and combined with quelites and Chilaca. In addition to that there are a large number of dishes made with HCS "(Cristina Carbajal, 2017).

The community has a lot of species of plants and animals for food processing, beverages and for medicinal use, among the most frequently mentioned were cantarito insect, arnica, borage, rockrose, rude and clin. "The insect cantarito is used to remove the narrow, a liquid containing used, is trapped with hands and is in croplands, although lately is difficult to find" (Elissete Ramirez, 2018).

In addition, it has developed ocoxal handicrafts are leaves falling from the pines and once dry bracelets, necklaces, baskets and mats are made. Despite having vast resources, members migrate in search of work, since the field and mycoturistics tours that begin to take place are temporary.

As a fifth step, from diagnosis, Diagram interrelationships of San Juan Atzningo, which is denoted that the biggest problem is in the biotic systemic element arises because if this element disappear there would be a strong sociocultural impact, it would be difficult to adapt and find their resilience.

Figure 2. Diagram Traditional- rational tourism planning San Juan Atzingo.

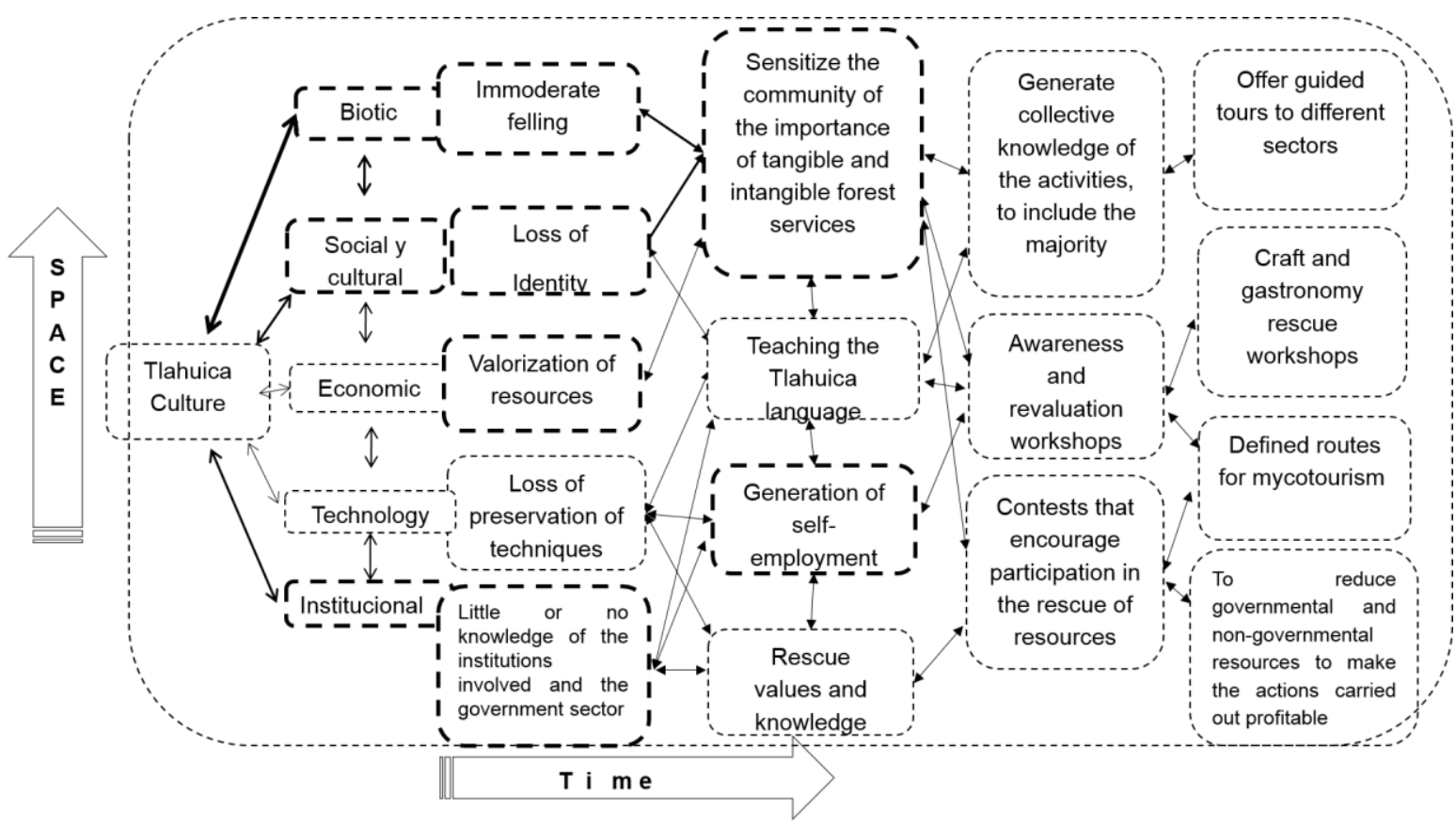

Source: Prepared based on results.

As is shown in Figure 1, the strongest relationships are focused in culture, which revolves around natural resources that account San Juan Atzingo, so the proposal of harmonic tourism that arises should include valorization of the forest area as a fundamental element of the systemic culture, like that the whole system could subsists in time and space.

Initially, projects in particular will have to seek harmony of subsystems, particularly among biotic, socio-cultural and institutional, as it is essential to promote collective work, from social cohesion to support various projects, also contemplate possible institutions that can support make tangible actions for natural resources and propose tourist routes, and mycoturism that minimize the impact of soil and erosion. 
Before potentiate tourism as a complementary activity, the diagram shows the need to promote awareness of the importance of natural and cultural resources that it has and the material goods and services provided to facilitate the rescue and preservation of traditional knowledge that they have, such as language Tlahuica, gastronomy, use of medicinal plants, mycotourism, among others.

\section{Discussion}

Diagnosis of San Juan Atzingo made through this methodology allows us to propose projects that strengthen the community, such as the mycotourism, practice in which from the harmonic interplay of traditional and rational knowledge can be improved, having an impact on quality of life, besides recovering knowledge that has been lost because of the lack of interest of the youngest generation.

These activities have been implemented in the community by members of the mushroom group of girls in connection with the academy, a task that can be on the one hand, generate the enhancement of community resources, and other teaching communities scientific to consider traditional knowledge as a fundamental element for the project proposal.

Applying a differential diagnosis to conduct a territorial planning based on the interplay of systemic elements and traditional and rational knowledge, provides a glimpse beyond just a lifting of generic and standardized data, because the feeling of community is not embodied. If it comes from the beginning, before proposing projects by institutions, will be held this type of diagnostic, communities may feel a fundamental part of the projects and leverage to generate other proposals related to tourism as a complementary activity, in order to reduce migration that occurs seasonally, and increasing the recovery and use of ancestral and cultural traditions.

By now, diagnostics that go beyond the collection of information, approaches and work areas are complicated, today the use of technologies facilitate data collection; however, people move away to form bonds and relationships that allow continuing the legacy of knowledge and traditions, so that is the main goal, and it can go beyond the information that we can get from books, internet and few visits. In the case of studies that are developed under this methodology, friendships between researchers and communities were forged, it allowed retrieve information not only emanating from the rational, but also information that comes from generation to generation, and has crossed the borders of the territory and time, leading to a dialogue of real and tangible knowledge.

\section{Conclusions}

From a fourth application of the methodology in a particular case (San Pedro Tultepec de Quiroga, Mexico, El Pericón, Guerrero, Malinalco, Mexico and Santa Fe de Antioquia Colombia), the window opens to the opportunity for the future research, since carrying out the interplay of traditional-rational knowledge, it can discern that emanate diagnosis and diagram, this methodology is engageable in any community, as in communities where it has been applied, have characteristics physical and socio different.

On the other hand, during the foundation and fieldwork, it was noticed that the concept of vernacular causes some interference in colloquial language when applying interviews and interrelate knowledge. On the one hand, the word vernacular is rooted in what is proper to a place, native language or local ethnic environment and also applies to architecture and (Quintriqueo and Quilaqueo, 2007); the traditional word not only has to do with a particular place, may have been born in a place and passed from one generation from one territory to another and continue with the traditions and customs, as is the case of this community.

From the socioterritorial contextualization in Mexico, it is essential to mention the culture that prevails in the temporal and spatial scales, which are the traditionalists, which lead to rethink the results of the interrelationship of knowledge, in order not only to baptize with a nickname to this interrelationship, but rather to give an identity to diagnosis and diagram, a task that is still pending. So that opens the door to a future applied research, to provide in the analysis of these interrelationships in various fields, including in the gastronomic and inquire about how to use, consume and transform different biophysical food sustainably subsystem. 
Another dialogue remains open is whether to have emanated diagnostics feel of communities, interrelated with scientific experience, the type of projects proposed, when to apply them in reality prevail over time, as the traditions of people, respecting the time of the land and customs of the other, interweaving personal interests to turn them into collective interests and translate them into a social welfare.

Author Contributions: Monica Gomez was awarded a scholarship, so she participated hard in the data collection. The PhDs Daniela Palmas, Andrea Jimenez- Ruiz and Rocio Serrano-Barquin wrote, constructed, carried out the conceptual foundation, collected and analyzed data, applied the methodology, integrated the conclusions and discussions. The master Rebeca Osorio contributed knowledge related to the concept of rural tourism (lines 63-98).

Funding: Please add: "This research received external funding" for project "Developed harmonic tourism, proposed a methodology for the appreciation of natural and cultural resources in the State of Mexico" registered with the Ministry of Public Education of Mexico (SEP).

Agreement: Especially agreement for Eliseete Carbajal Ramirez for all her help in these years, for all the information and for her amiability.

\section{Key Informant:}

1. Anonymous, 65, Tlahuica community. Information obtained in August 2017.

2. Mrs. Cristina Carbajal Barrón, Chairperson of the Hongueras Nebejolchjo Pjiekakjoo, San Juan Atzingo. Information obtained from August 2017 to August 2018.

3. Mrs. Magdaleno Leoba Baldomero, Treasurer Group Hongueras Nebejolchjo Pjiekakjoo, San Juan Atzingo. Information obtained from August 2017 to March 2018.

4. Ms. Margarita Nepomuseno Procopio, Treasurer Group Hongueras Nebejolchjo Pjiekakjoo, San Juan Atzingo. Information obtained from August 2017 to March 2018.

5. Sergio Ramírez Raymundo, guide tours Mycoturistics. Information obtained from August 2017 to August 2018.

6. Ezequiel Carbajal Ramirez, San Juan Atzingo. Information obtained from August 2017 to August 2018.

7. Mario Alberto Ruperto Alejandro, farmer town of Lomas de Teocaltzingo. Information obtained from August 2017 to March 2018.

8. Eliseete Carbajal Ramirez, manager of Hongueras Nebejolchjo project Pjiekakjoo San Juan Atzingo community. Information obtained in a period comprising August 2017 to August 2018,

9. Ancelmo Clara González, Second Councilor for Tourism, Urban Development, Municipal Bando Review, Rules and Housing, June 2018

\section{References}

1. Agüero, G, Urtubey, L. \& Vera, D. (2008) "Concepts, beliefs and rationality." Editorial Brujas. First edition. Pag. 204. obtained on March 17, 2017 from: https://books.google.com.mx/books?id=RVMrhlvvl60C\&printsec=frontcover $\# \mathrm{v}=$ onepage\&q\&f=false

2. Alvarez, R. (2006). Rural tourism: an agribusiness development of rural areas, in Vieites, Carlos. (Ed.), Alternative Agronegocios. Focus, importance and basis for the generation of non-traditional agricultural activities. Buenos Aires: Southern Hemisphere.

3. Argueta, G. and Varela, A. (2014). Sustainable tourism planning from a systemic approach. Tourism Management, 1 (21), 9-32.

4. Barrera, E. (2006). Rural tourism: an agribusiness development of rural areas, in Vieites, C. (ed.), alternative Agronegocios. Focus, importance and basis for the generation of non-traditional agricultural activities. Buenos Aires: Southern Hemisphere.

5. White, M. \& Rivero, H. (2003). Agrotourism, an alternative to revalue rural agroindustry as a mechanism for local development: Technical / document Hernando Riveros S. Marvin Blanco M. - Lima: IICA: PRODAR, 2003 p.33 (Working Paper Series / PRODAR).

6. Bullón, R. \& D. Bullón (Ed). (2008). Rural tourism. A global approach. Mexico: Trillas. 
7. CDI (2010) Costa Drinking, Ana Maria; de Araujo Gastal, Suana and Menchase Renata.

8. Cuevas, P. (2010) .Importance of biological resilience as a possible indicator of the conservation status of ecosystems: implications for management plans and conservation of biodiversity. Biological, 12 (1), 1-7.

9. Farrell, B. \& Twining-Ward, L. (2005). Seven steps towards sustainability: Tourism in the context of the new knowledge. Journal of Sustainable Tourism.13 (2), 109- 122.

10. FERTINOVA. (2018). Triple Data Sheet 16-16-16. Available in:http://www.fertinova.mx/sites/default/files/FICHA\%20TRIPLE\%2016.pdf

11. Grimm, V. \& Calabrese, J. (2011). What is resilience? A short instruction. In. Deffaunt G. and N. Gilbert (eds) Viability and Resilience of Complex Systems: Concepts, Methods and Case Studies of Ecology and Society (pp.3-13) Heidelberg Springer.

12. Gutierrez, C., Sancho, A., Szmulewicz, P. \& Cabrera, B. (2014). Resiliency key factor in the recovery of tourist destinations affected by natural disasters. Lecture at VI Latin American Congress of Tourism Research. Neuquén, from 25 to 27 September 2014

13. Gutierrez, J. (2013). Geographical Research: Fundamentals, Methods and Tools. Editorial Dunken.

14. Hall, M., Payag, G. \& Amore, A. (2017). Tourism and Resilience. Individual, Organizational and Destination Perspectives. US: Edwards Brothers Malloy, Inc. UK: Short Run Press.

15. Herrera, G. \& Rodriguez, G. (2016). Resiliency and tourism: the case of the city of Baños de Agua Santa. HOLOS, 229- 250.

16. Herrera, G. \& Rodriguez, G. (2017). Tourism and Resilient Enterprise Systems: Adaptability Critical Factors in Baños de Agua Santa - Ecuador. Gestão magazine and Secretariat, 8 (1), 01-25. 2017 doi: https://doi.org/10.7769/gesec.v8i1.606.

17. Jimenez-Ruiz A, H Thome-Ortiz \& C Burrola. (2016). Biocultural heritage, tourism and mycological ethnoknowledge. El Periplo Sustentable journal. Mexico, 29 (30): 180- 205. DOI: 10.21854 / eps.v0i30.2529

18. Jimenez-Ruiz, A., Thome-Ortiz, H., Espinoza-Ortega, A., \& Vizcarra, I. (2017). Recreational use of wild edible mushrooms: mycotourism cases in the world with an emphasis on Mexico. FOREST, 38 (3), 447-456. [Online]:http://revistas.uach.cl/index.php/bosque/article/view/821ABNT (2 January 2018).

19. Ibañez, R. \& Angels, M. (2012) .Indicators tourism sustainability in Mexico. Environment and tourism policy in Mexico Volume I: Ecology, biodiversity and tourism development, 47.

20. Lazarus, A. (2008). Mycological use as a means of rural development in Spain: the commercial and recreational aspects. Geography Annals 28 (2): 111-136.

21. Leff, E. (2002). The transition to sustainable development: Prospects for Latin America and the Caribbean. Mexico: Secretary of Environment and Natural Resources, National Institute of Ecology, Autonomous Metropolitan University and United Nations Environment Program.

22. Leff, E. (2006). Adventures of environmental epistemology: the articulation of science, the knowledge dialogue. Mexico: Siglo XXI.

23. Macario Oliveira, V., Raisin, C., \& Ataíde, G. (2013). Sustainability indicators for tourism: A proposal for monitoring using analysis criteria. Studies and prospects in tourism, 22 (2), 177-197.

24. Maldonado, C. \& Hernandez, G. (2017). Guide to self-sustainability: community tourism destinations. Retrieved on December 16, 2017: https://www.ilo.org/americas/publicaciones/WCMS_185024/lang-es/index.htm

25. Martinez, L. (2018). Analysis of sports tourism model Oliva Nova Beach \& Golf Resort. Proposals for improvement and adaptability to other cases. Unpublished doctoral dissertation, Valencia, Spain. February 2018.

26. Masera O., M. \& Lopez Ridaura Astier, S. (2009). Sustainability and natural resource management: the evaluation framework MESMIS, UNAM-Institute of Ecology, ROTATE, Oxford University Press Mexico, SA de CV 1999.

27. Morin, E. (2005). My demons. 2nd ed. Barcelona: Kairos.

28. Nogar, G. and Capristo, V. (2010). New scenarios for rural areas. Rural tourism as an emerging process. In Nogaro, Graciela and Jacinto, Guillermina (2010) Comp. Rural areas theoretical approaches and intervention processes in rural tourism. Buenos Aires. La Colmena Cap. V

29. Olvera, J., Cazorla, A., \& Ramirez, B. (2009). Rural development policy in the European Union and the LEADER initiative, a successful experience. Region and Society, 21 (46), 03-25. Retrieved on September 12, 2018, of http://www.scielo.org.mx/scielo.php?script=sci_arttext\&pid=S187039252009000300001\&lng=es\&tlng=es 
30. OMPI. (2002).Wintellectual property and traditional knowledge. Brochure No. 2. Geneva: World Intellectual Property Organization.

31. OMPI. (2018). Guide documentation of traditional knowledge. Switzerland: World Intellectual Property Organization. Geneva World Intellectual Property Organization.

32. Ortiz, S., Guiascón, \& Gustavo R., O. (2015). Scientific note: Medicinal Use of Wildlife by Indigenous Tlahuicas in Ocuilan, Mexico. Ethnobiology, 10 (3), 28-33.

33. Osorio, R., Espeitx, E. \& Serrano- Barquin, Rocio (2015) Patrimonialization of aged cheese and rural tourism in Zacazonapan, State of Mexico. Turydes magazine: Tourism and Development, N. 19 [Online]: http://www.eumed.net/rev/turydes/19/zacazonapan.html (23 November 17).

34. Pacifex (2014). Safety Data Sheet 16. Pacifex HDS triple fertilizer SA de CV Available in: http://www.pacifex.com.mx/pdf/HDS\%20T-16\%202014.pdf 05/02/2018

35. Palmas, D., Serrano-Barquín, R, Gutierrez, J, Cruz, G., \& Favila, H. (2014). Theoretical and methodological model for the study of harmonic tourism and local development. Investigaciones Turísticas, [S.1.], n. 7, p. 23-46, jun. 2014. ISSN 2174-5609. In: <https://investigacionesturisticas.ua.es/article/view/2014-n7-modeloteorico-metodologico-para-el-estudio-del-turismo-armonico-y-el-desarrollo-local>. Available at: 07 jul. 2019 doi: https://doi.org/10.14198/INTURI2014.7.02.

36. Palmas, D., Serrano-Barquin,R \& Gutiérrez, J (2017). Methodology of harmonious tourism. A proposal for evaluation of knowledge for San Pedro Tultepec de Quiroga, State of Mexico. Nova Scientia, 9 (19), 717 750. Available at: <http://www.scielo.org.mx/scielo.php?script=sci_arttext\&pid=S200707052017000200717\&lng=es\&nrm=iso>. ISSN 2007-0705. http://dx.doi.org/10.21640/ns.v9i19.1073.

37. Palmas, D., Serrano-Barquin, R \& Gutiérrez, J. (2018). Harmonic Tourism Theoretical and Methodological Model: Application to the Central Highlands of Mexico ". Athens Journal of Tourism, 2241-8148 e-ISSN, published online 12 July 2018. Available at: https://www.athensjournals.gr/tourism/2018-5-3-2Castrejon.pdf

38. Perez-Ramirez, C. \& Zizumbo, L. (2014) Rural tourism and communality: socio territorial San Juan Atzingo impacts, Mexico. Notebooks Rural Development [Sl], v. 11, n. 73, p. 17-38, July. 2014. ISSN 2215-7727. [Online]: <http://revistas.javeriana.edu.co/index.php/desarrolloRural/article/view/6108> (24 October 2017).

39. Municipal Development Plan Ocuilan (2016- 2018). Government of the State of Mexico. Mexico: City of Ocuilan.

40. PMDU Ocuilan (2016- 2018). Government of the State of Mexico. Mexico: City of Ocuilan.

41. Quintriqueo, S. \& Quilaqueo, D. (2007). "Vernacular educational skills for curriculum innovation in Mapuche context." Journal of Psychology. 97-121.

42. Quiñonez, H. \& Barreto, F. (2014). Vernacular knowledge as a generator of local development. Geographic perspective, (17), 259-281.

43. Ramirez, E. (2017). Ethnomycology Tlahuica piejkakoo area. Intercultural University of the State of Mexico. San Felipe del Progreso.

44. Royal Spanish Academy (2016). Spanish dictionary. Spain: RAE

45. Requier-Desjardins, D. (2006). SIAL local agritourism system: territorial quality, typical food products and agritourism. International Solidarity Tourism Forum March 25, 2006.

46. Roman F. \&Ciccolena, M. (2009). Rural tourism in Argentina. Concept, situation and prospects. Argentina: Inter-American Institute for Cooperation on Agriculture.

47. Sabatino, M. (2016). Economic crises and resilience. Resilience Capacity and Competitiveness of the enterprises. Journal of Business Research, 1924- 1927.

48. Sanchez, J. \& Mata, G. (Ed). (2012). "Edible and Medicinal Mushrooms in Latin America: Researchand development in a multicultural environment "El Colegio de la Frontera Sur -. Institute of Ecology, AC Tapachula, 393 pp.

49. Sancho, A. \& Gutierrez, C. (2010). Crisis in the tourism sector?: a resilient attitude towards sustainability. Naya Team. The 4th Latin American Congress of Tourism Research. Held in Montevideo, Uruguay, from 22 to 24 September 2010

50. Sancho, A., Garcia, G. \& Rozo, E. (2007). Comparison of sustainability indicators for developed destinations, developing and vulnerable populations. Annals of Tourism Research, 9 (1), 150-177.

51. SECTUR (2004) Alternative Tourism, a new form of tourism. Mexico: Federal Ministry of Tourism. 
52. Serrano-Barquin, R. (2006) "Harmonic Tourism and integrative planning participant, to sustainable local development" in Osorio M. and Castillo M. (Coord.) Environment Tourism. Vol. 3. Perspectives. UAEM, Toluca, pp. 111-135

53. Serrano-Barquin, R. Chavez, R. Serrano, R. (2008) "Harmonic tourism and local development from the perspective of sustainability and complex systems". Memories of the International Symposium on Selected Topics in Complex Systems Engineering Applied to Sustainable Animal, Morelia, Michoacan Production. Mexico: Technological Institute of Morelia Valley and the State Council of Science and Technology.

54. Serrano-Barquín, R, Perez-Ramirez, C., Manjarrez-Campos, E., \& Gonzalez-Melgarejo, L. (2010). Harmonic tourism as a sustainable alternative: For a community in the state of Mexico. Studies and prospects in tourism, 19 (6), 970-993. Retrieved on March 29, fromhttp://www.scielo.org.ar/scielo.php?script=sci_arttext\&pid=S1851$17322010000600006 \& \operatorname{lng}=\mathrm{es} \& \ln \mathrm{ln}=\mathrm{es}$.

55. Thomé- Ortiz, H. (2007). The rural tourism in the northern highlands of Oaxaca. Comparative study of cases of the municipalities of Ixtlan de Juarez and Calpulálpam Mendez. Thesis

56. Varisco, Mg. (2013). Tourism system. Subsystems, dimensions and trans concepts. Argentina. Available in:http://nulan.mdp.edu.ar/2208/1/varisco.2013.pdf

57. Velarde, I., Garat, J., Marasas, M. \& Seibane, C, 2014, local production systems in the Rio de La Plata, Argentina: conclusion of actors, differentiation and recovery of typical products. P. 6.

58. Velazquez, M., \& Jimenez, A. (2018). An exploratory vision of community futro Cancun: social consequences of tourism growth model in the municipality of Benito Juarez, https://rperiplo.uaemex.mx/article/view/9067

59. Vera-Rebollo, J. (2001). Planning and management of sustainable tourism development: proposals for the creation of a system of indicators. 